\title{
Geometric Tower: game para auxílio no ensino lógico-matemático e espacial
}

\author{
Gabriel Pereira $^{1}$, Kelvin Itaboray $^{1}$, Lucas Batista ${ }^{1}$, Marcio Galvao $^{1}$, \\ Pedro Moises $^{1}$, William Nakagawa ${ }^{1}$ \\ ${ }^{1}$ Instituto de Ciências Exatas - Universidade Federal de Viçosa Campus Rio Paranaíba (UFV-CRP) \\ Caixa Postal 22 - 38.810-000 - Rio Paranaíba - MG - Brasil \\ \{gabriel.g.pereira, lucas.b.fialho,kelvin.itaboray, william.nakagawa\}@ufv.br \\ marcio.wanderson.si@gmail.com, rofpedromoises@yahoo.com.br
}

\begin{abstract}
This article aims to show the Planning, Development and Implementation of a game based on mathematical concepts to support logical reasoning and geometric teachings, with a focus on pedagogical area and Information Technology.

Resumo. Este artigo tem por objetivo mostrar o planejamento, desenvolvimento e implementação de um game baseado em conceitos matemáticos para auxilio no ensino de raciocínio lógico e geométrico, com foco na área pedagógica e de tecnologia da informação.
\end{abstract}

\section{Introdução}

A Geometria é uma disciplina que está presente nos currículos escolares e é utilizada no cotidiano do aluno de forma sutil sem que o mesmo o perceba. Muitos dos alunos que estudam essa matéria não conseguem visualizar suas aplicações de maneira clara e a julgam ser desnecessária. Segundo [Pereira 2014] utilizando os conhecimentos geométricos fazem com que a percepção matemática do dia a dia fique mais compreensiva e significativa, desenvolvendo a criatividade e o raciocínio lógico dedutivo. Para [dos Santos Silva 2016] o estudo da geometria tem se tornado cada vez mais ausente nas salas de aulas, mas é importantíssimo para o aprendizado, pois desenvolve nos alunos características que serão utilizadas em outras áreas da educação.

Neste contexto, este presente trabalho propõe uma alternativa para tornar mais fácil o contato do aluno com a geometria, tornando-o mais interativo e agradável ao aluno. Este processo pode ser facilitado através do processo de gamificação. Este, quando aplicado na área de educação, consiste em criar uma abordagem com conceitos de jogos eletrônicos para facilitar o ensino de um determinado assunto. [FREIRE 2015] diz que utilizando jogos para lecionar uma disciplina faz com que o aluno se sinta disposto a aprender e fique motivado, visto que a geração atual tem maior contato com jogos eletrônicos. Além de ensinar o conteúdo que um jogo educacional trata, [Savi and Ulbricht 2008] também cita números benefícios que o mesmo traz, como facilitar o aprendizado, desenvolver habilidades cognitivas, capacidade de identificação (associação do jogador com a personagem), socialização e melhora da coordenação motora.

O objetivo principal desta publicação é a criação de um jogo eletrônico em que o foco é associar figuras semelhantes, com áreas e perímetros de determinadas formas 
V Congresso Brasileiro de Informática na Educação (CBIE 2016)

Anais dos Workshops do V Congresso Brasileiro de Informática na Educação (CBIE 2016)

geométricas. Com isso, espera-se auxiliar o desenvolvimento do raciocínio lógico matemático e espacial de crianças cursando o ensino fundamental, ajudar no seu aprendizado e aprimorar a memória e o reconhecimento de cores e formas, bem como no aprendizado da geometria.

\subsection{Metodologia}

Para o desenvolvimento deste trabalho utilizaremos processo ágil de desenvolvimento de Sistemas de Realidade Virtual, que possui cinco etapas e podem ser desenvolvidas iterativamente [Mattioli et al. 2009].

$\mathrm{Na}$ primeira etapa, que é a análise de requisito, obteve-se o escopo, storyboard e foram definidos os requisitos básicos do sistema virtual. Segundo [Leme da Silva and Valente 2013] há uma ligação entre espaço e forma, de um lado processos pedagógicos ajudam no entendimento do espaço e de outro a geometria com reconhecimento de formas abstratas. Dede a pré-escola as crianças conseguem discriminar características como aberto e fechado, e crianças de mais idade identificam linhas retas de lados curvos e reconhecem formas como quadrados e losangos. Por este motivo foi definido o público alvo do jogo de crianças dos primeiros anos do ensino fundamental.

Na segunda etapa, que é a de projeto, foram definidas as ferramentas de desenvolvimento que serão utilizadas para a construção do game. A principal ferramenta utilizada é o software Unity, que além do espaço para a criação do jogo, oferece uma base de dados com tutoriais, documentação dentre outros recursos para auxiliar no desenvolvimento da aplicação. Também será utilizado o programa Photoshop para a criação de sprites gráficos em 2D.

$\mathrm{Na}$ terceira etapa, que é a de implementação, foram construídas as fases e criadas as imagens e sprites para cada uma delas. Nesta etapa, também foi desenvolvida toda a lógica do game. Todos os scripts referentes a programação do jogo foram escritos, utilizando as linguagens C\# e JavaScript, formando assim as engines e a física do jogo.

Na quarta etapa, que é a de avaliação, foram realizados testes no game para verificar a usabilidade e desempenho do mesmo. O jogo foi disponibilizado para que crianças do ensino fundamental de uma escola interagissem com o jogo e foi realizado um questionário avaliativo.

Na quinta e última etapa, que é a de implantação, o game será instalado em escolas para alunos do ensino fundamental. 
V Congresso Brasileiro de Informática na Educação (CBIE 2016)

Anais dos Workshops do V Congresso Brasileiro de Informática na Educação (CBIE 2016)

\section{Trabalhos Relacionados}

[Pedro et al. 2012] apresentou uma proposta semelhante a deste trabalho, porém através de um aplicativo mobile. Abordando o conceito de geometria interativa o usuário pode, a partir de um espaço em branco na tela do dispositivo móvel, utilizar gestos para criar diferentes pontos. Estes podem ser assimilados para serem formados retas, que podem ser usadas para criar interseções, criando figuras geométricas entre elas. Esta ferramenta possibilita ao usuário a aprender e utilizar todos estes conceitos básicos de geometria, motivando o aluno a criar diferentes formas.

Outro projeto semelhante é o de [de Moraes et al. 2008], em que ele propõe criar virtualmente um jogo chamado GeoPlano, inventado em 1961 por Caleb Gattegno. Na versão virtual, os autores propõem um ambiente onde o usuário jogará contra uma IA (inteligência artificial). O jogo acontece em turnos entre os mesmos, em que existe uma área plana de tamanho limitado onde pode-se criar figuras geométricas. Para vencer a rodada, o jogador deve criar formas que impossibilite ou dificulte a IA de realizar suas jogadas. O jogador irá ganhar caso consiga montar mais formas do que o programa, sem desrespeitar as regras do jogo. Além de ensinar sobre as formas geométricas, o jogo também desenvolve o raciocínio de seus jogadores, visto que deve-se criar uma boa estratégia para vencer uma rodada do jogo.

\section{Arquitetura do Sistema}

O jogo foi desenvolvido para tratar o conceito de formas geométricas em 3 tipos diferentes, cada um retratado em uma fase diferente. O jogador irá manipular um personagem, que irá pegar os objetos presentes na fase, e encaixá-los nos blocos correspondentes a forma. Para melhor representar o conceito do jogo, será apresentado uma estrutura, simplificada na figura 1:

- Usuário: Ator que manipula todo o ambiente virtual, responsável por controlar o personagem que faz as ações no jogo;

- Interface Gráfica: Interação entre o usuário e o ambiente virtual;

- Menu: Menu que dá início ao jogo, onde podem ser vistas as instruções do jogo, assim como acessar a fase inicial;

- Personagem: Objeto em 2D/3D que fará as principais ações do jogo, que pegará os objetos para encaixar nos blocos correspondentes.

- Fase 1: A primeira fase do jogo, totalmente em 2D, onde serão trabalhados conceitos mais simples de geometria, apenas em um plano;

- Fase 2, 3 e 4: Serão tratados conceitos mais complexos como número de lados, perímetro, área das figuras geométricas;

- Fase 5: Por fim, a última fase misturará conceitos 2D e 3D, e fornecerá um desafio maior para o jogador, com objetos mais difíceis de serem executados. Esta última etapa será realiada em futuros projetos. 
V Congresso Brasileiro de Informática na Educação (CBIE 2016)

Anais dos Workshops do V Congresso Brasileiro de Informática na Educação (CBIE 2016)

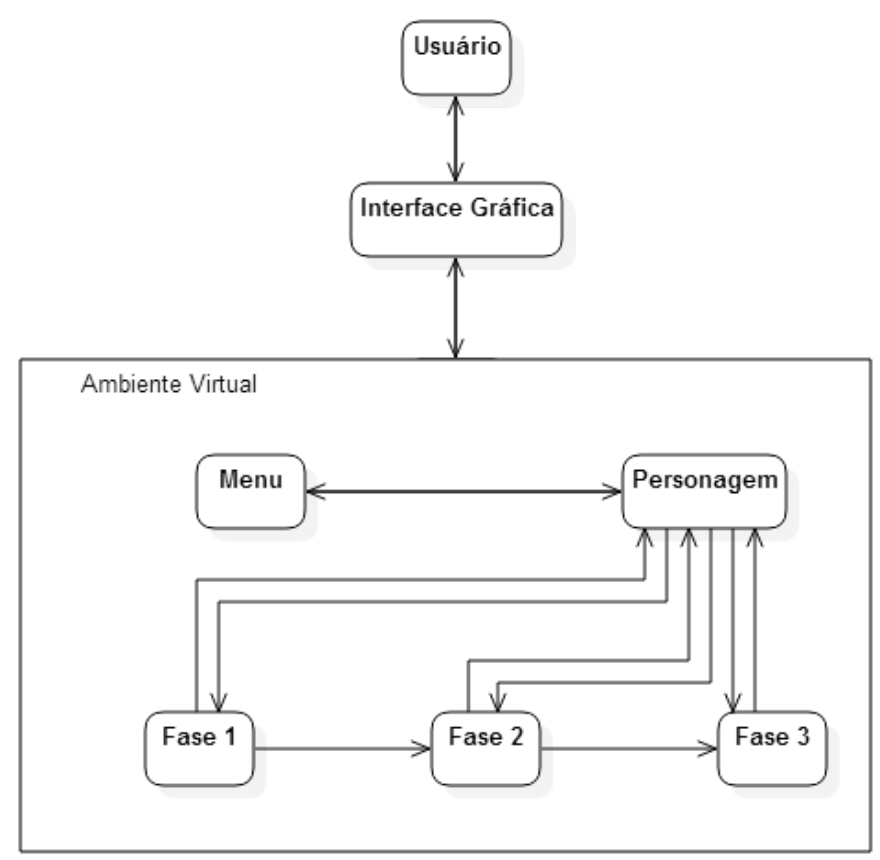

Figura 1. Arquitetura - Estrutura Simplificada

\section{Funcionalidade do Sistema}

Ao abrir o jogo, tem-se a tela inicial, com as opções de iniciar o jogo, ver as instruções de como jogar, créditos para ver quem são os criadores e sair para encerrar o jogo.

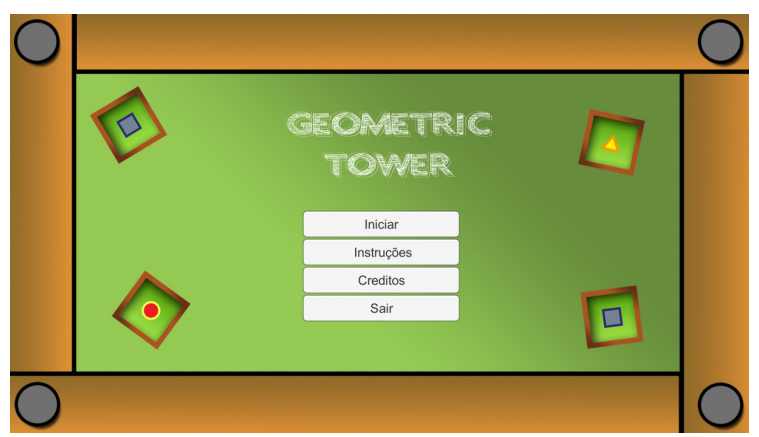

Figura 2. Geometric Tower - Menu inicial

O escopo do jogo consiste em um cenário com duas torres formadas por blocos que contém diferentes figuras geométricas. Existem 4 canos no jogo, de onde sairão variados tipos de figuras geométricas que poderão ser coletadas pelo personagem principal, que deverá encaixar a mesma no bloco de uma das torres, com a figura geométrica correspondente.

Ao iniciar a fase o jogador terá vinte segundos em seu cronômetro, caso o tempo acabe, ele perderá. O jogo terá um sistema de pontos, onde o jogador poderá ganhá-los ao encaixar uma figura no bloco certo, assim como poderá conseguir mais 3 segundos no cronômetro a cada encaixe. Quanto mais alto estiver o bloco, mais pontos ele ga- 
V Congresso Brasileiro de Informática na Educação (CBIE 2016)

Anais dos Workshops do V Congresso Brasileiro de Informática na Educação (CBIE 2016)

nhará. O jogador iniciará cada fase com três vidas, que poderão ser perdidas se uma figura geométrica cair na cabeça do personagem.

Quando o jogador entrar na opção "Iniciar", ele será direcionado para a primeira fase, que consiste em associar figuras geométricas em 2D. Esta fase contém apenas formas geométricas simples, como quadrados, triângulos e círculos. Para vencê-la, o jogador deverá conseguir 1500 pontos.

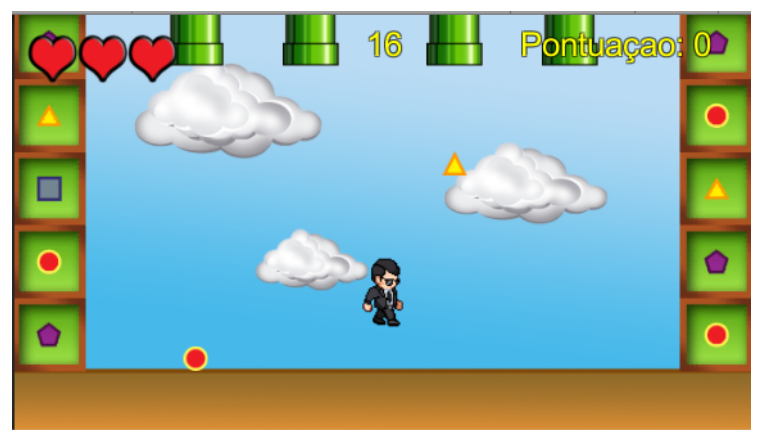

Figura 3. Geometric Tower - Primeira Fase

Ao conseguir a pontuação necessária, o jogador irá para a segunda fase, que começará com o número de lados de cada figura geométrica que estará inscrito em cubos, em que o jogador deve selecionar e anexar as laterais com as figuras geométricas correspondentes. O jogador nesta fase terá que fazer 2000 pontos. Na terceira fase o jogador terá que selecionar os perímetros e na quarta fase, o jogador terá que selecionar a área de cada figura geométrica e levar até o cubo lateral correspondente com a forma geométrica inscrita. A pontuação será respectivamente 2500 e 3000 pontos. Ao conseguir a quantidade necessária de pontos, o jogador será parabenizado por terminar o jogo.

\section{Análise e discussão dos resultados}

A coleta dos resultados foi retirada através da II Mostra de Jogos ocorrida no hall do Pavilhão de Aulas da Universidade Federal de Viçosa, na qual o jogo foi exposto para crianças convidadas de uma escola pública da cidade de Rio Paranaíba, incluindo várias pessoas, alunos e professores de diversos cursos do Campus em que os mesmos puderam fazer o teste do jogo.

Após o teste foi realizado o preenchimento de um questionário com 26 entrevistados diferentes que testaram o jogo. O questionário contém 10 perguntas relacionadas a usabilidade do jogo, em que a pessoa que o testou poderia avaliar cada quesito em uma escala de 1(um) a 5(cinco) como grau de satisfação. O valor 1(um) significa que a experiência com o jogo foi péssima e o valor 5(cinco) simboliza que a experiência foi ótima.

A Tabela 1 mostra os resultados obtidos após as respostas dos usuários. A cada pergunta é apresentado de acordo com o grau de satisfação a quantidade de respostas obitidas. 
V Congresso Brasileiro de Informática na Educação (CBIE 2016)

Anais dos Workshops do V Congresso Brasileiro de Informática na Educação (CBIE 2016)

Tabela 1. Questionário de usabilidade.

\begin{tabular}{|c|c|c|c|c|c|c|}
\hline \multirow{2}{*}{ Perguntas } & \multirow{2}{*}{ Descrição } & \multicolumn{5}{|c|}{ Grau de satisfação } \\
\hline & & 1 & 2 & 3 & 4 & 5 \\
\hline 1 & O jogo é divertido? & & & 5 & 1 & 20 \\
\hline 2 & $\begin{array}{l}\text { O jogo é auto descritivo? Ou seja, ele te informa } \\
\text { como realizar as tarefas? }\end{array}$ & 1 & 2 & 2 & 2 & 19 \\
\hline 3 & $\begin{array}{l}\text { Você se sentiu confortável ao controlar o persona- } \\
\text { gem? }\end{array}$ & & 2 & & 6 & 18 \\
\hline 4 & $\begin{array}{l}\text { Você achou fácil se locomover pelo ambiente? Ou } \\
\text { seja, a navegação do personagem estava boa? }\end{array}$ & & 2 & 4 & 2 & 18 \\
\hline 5 & $\begin{array}{l}\text { Você se sentiu à vontade com todas as funções do } \\
\text { jogo? }\end{array}$ & & & 3 & 6 & 17 \\
\hline 6 & $\begin{array}{l}\text { O jogo evolui em um ritmo adequado e não fica } \\
\text { monótono? }\end{array}$ & 1 & 3 & 2 & 2 & 18 \\
\hline 7 & O jogo é fácil de utilizar e entender? & 1 & & 5 & 3 & 17 \\
\hline 8 & O design da interface do jogo é atraente? & & 1 & 1 & 4 & 20 \\
\hline 9 & Me senti estimulado a aprender com o jogo? & & & 2 & 8 & 16 \\
\hline 10 & $\begin{array}{l}\text { Esse jogo pode ser entendido e usado por qualquer } \\
\text { aluno, com pouca ou muita experiência no uso de } \\
\text { computadores? }\end{array}$ & 1 & & 1 & 3 & 21 \\
\hline
\end{tabular}

Em vista dos resultados coletados, nota-se uma boa aceitação do jogo pelos alunos que o testaram. A maior parte dos alunos achou o jogo divertido, e se sentiu estimulado. Um problema notável que foi percebido é a dificuldade em se acostumar com o ambiente e o controle do personagem pela primeira vez, visto que é necessário ter instrução do mesmo. Porém, uma vez acostumado com o funcionamento do jogo, o mesmo se torna de fácil entendimento e usabilidade, tornando-se viável a ser utilizado em um ambiente educacional.

\section{Trabalhos Futuros}

Até o momento o jogo tem implementado as fases iniciais usando figuras geométricas em 2D. Pretende-se adicionar futuramente a interação do jogador com formas geométricas 3D, tornando o jogo mais desafiador e possibilitando abranger mais conceitos de geometria. Espera-se também criar ferramentas e itens que possam auxiliar o jogador durante as fases, onde o mesmo possa interagir com um ambiente mais dinâmico e receber ajuda em determinados momentos, caso esteja tendo dificuldades.

Será criado também um placar, onde serão comparadas as maiores pontuações adquiridas no jogo.

\section{Considerações Finais}

Como as áreas da matemática e da geometria são duas matérias que requerem bastante estudo e seu aprendizado pode acabar se tornando monótono, utilizar um jogo educacional 
V Congresso Brasileiro de Informática na Educação (CBIE 2016)

Anais dos Workshops do V Congresso Brasileiro de Informática na Educação (CBIE 2016)

para passar este conhecimento é uma maneira de trabalhar este problema de forma mais agradável. Por fim, ao utilizar a realidade virtual e a computação gráfica como auxílio, é possível criar meios que tornem um certo estudo ou aprendizado mais dinâmico, e faça com que o aluno se interesse mais pelo assunto quanto mais ele estudar através dessa realidade.

Por fim, pode-se constatar que é possível utilizar métodos lúdicos aliado a gamificação para desenvolver um jogo educacional e que o jogo necessita apenas de um auxílio parcial do professor, e com isso a criança pode aprender se divertindo.

\section{Referências}

de Moraes, M. B. S., Dutra, D. L., dos Anjos, U. U., do Rego, R. G., de Moraes, R. M., and dos Santos Machado, L. (2008). Geoplano: Um jogo educacional inteligente para o ensino de geometria plana.

dos Santos Silva, Brenda Silva, M. A. (2016). A contextualização dos conhecimentos geométricos na educação de jovens e adultos: Um estudo da rede pública municipal de alcobaça, bahia. IV SEMAT-Práticas e Saberes na Formação de Professores que Ensinam Matemática, 1(1).

FREIRE, C. d. C. (2015). Gamificação e ead: Importância e possibilidades para uma educação com foco no aluno. Trabalho de Final de Curso. Instituto de Matemática e Estatística. LANTE-Laboratório de Novas Tecnologias de Ensino. Universidade Federal Fluminense $(R J)$.

Leme da Silva, M. C. and Valente, W. R. (2013). Aritmética e geometria nos anos iniciais: o passado sempre presente.

Mattioli, F. E., Lamounier Jr, E. A., Cardoso, A., Alves, N. M., and Muniz, M. (2009). Uma proposta para o desenvolvimento ágil de ambientes virtuais. SBC. Anais do WRVA.

Pedro, L. Z., Borges, S. S., Lopes, A. M., Souza, J. P., Brandão, A. A., Brandão, L. O., and Isotani, S. (2012). Projeto e desenvolvimento de um aplicativo de geometria interativa para dispositivos móveis. In Anais do Simpósio Brasileiro de Informática na Educação, volume 23.

Pereira, J. F. (2014). O ensino da geometria na sala de aula do ensino médio e uma experiência com o pibid-uepb.

Savi, R. and Ulbricht, V. R. (2008). Jogos digitais educacionais: benefícios e desafios. RENOTE, 6(1). 